riginal research

\title{
Genetic diversity of Leishmania amazonensis strains isolated in northeastern Brazil as revealed by DNA sequencing, PCR-based analyses and molecular karyotyping
} João Paulo C de Oliveira1, Flora Fernandes', Angela K Cruz², Viviane Trombela², Elisângela Monteiro ${ }^{3}$, Anamaria A Camargo ${ }^{3}$, Aldina Barral ${ }^{1}$ and Camila I de Oliveira*1

Address: ${ }^{1}$ Centro de Pesquisas Gonçalo Moniz, FIOCRUZ, Rua Waldemar Falcão, 121, 40296-710, Salvador, BA, Brazil, ${ }^{2}$ Faculdade de Medicina de Ribeirão Preto, USP, Av. Bandeirantes 3900, 14049-900, Ribeirão Preto, SP, Brazil and ${ }^{3}$ Ludwig Institute for Cancer Research, R. Prof. Antonio Prudente, 109, 4th Floor, 01509-010, São Paulo, SP, Brazil

Email: João Paulo C de Oliveira - jp-ol@bol.com.br; Flora Fernandes - flozinha123@yahoo.com.br; Angela K Cruz - akcruz@fmrp.usp.br; Viviane Trombela - vtrombel@rbp.fmrp.usp.br; Elisângela Monteiro - alfaelis@yahoo.com;

Anamaria A Camargo - anamaria@compbio.ludwig.org.br; Aldina Barral - abarral@bahia.fiocruz.br; Camila I de

Oliveira* - camila@bahia.fiocruz.br

* Corresponding author

Published: 21 June 2007

Kinetoplastid Biology and Disease 2007, 6:5 doi:10.1 186/1475-9292-6-5

This article is available from: http://www.kinetoplastids.com/content/6/1/5

(c) 2007 de Oliveira et al; licensee BioMed Central Ltd.

This is an Open Access article distributed under the terms of the Creative Commons Attribution License (http://creativecommons.org/licenses/by/2.0), which permits unrestricted use, distribution, and reproduction in any medium, provided the original work is properly cited.
Received: 23 November 2006

Accepted: 21 June 2007

\begin{abstract}
Background: Leishmania (Leishmania) amazonensis infection in man results in a clinical spectrum of disease manifestations ranging from cutaneous to mucosal or visceral involvement. In the present study, we have investigated the genetic variability of 18 L. amazonensis strains isolated in northeastern Brazil from patients with different clinical manifestations of leishmaniasis. Parasite DNA was analyzed by sequencing of the ITS flanking the $5.8 \mathrm{~S}$ subunit of the ribosomal RNA genes, by RAPD and SSR-PCR and by PFGE followed by hybridization with gene-specific probes.

Results: ITS sequencing and PCR-based methods revealed genetic heterogeneity among the $L$. amazonensis isolates examined and molecular karyotyping also showed variation in the chromosome size of different isolates. Unrooted genetic trees separated strains into different groups.

Conclusion: These results indicate that $L$. amazonensis strains isolated from leishmaniasis patients from northeastern Brazil are genetically diverse, however, no correlation between genetic polymorphism and phenotype were found.
\end{abstract}

\section{Background}

Leishmania is an intracellular protozoan parasite that infects humans and causes a wide spectrum of diseases known as leishmaniases. Leishmaniases are endemic in 88 countries, where 350 million people live the risk of infection. In the American continent, leishmaniasis is caused by a different number of species and infection with L. amazonensis, in particular, produces a wide spectrum of clinical diseases [1]. Severity varies from localized cutaneous leishmaniasis (LCL), the most common clinical manifestation, to diffuse cutaneous leishmaniasis (DCL). LCL, in Brazil, is associated with species belonging to both 
Viannia and Leishmania sub-genus whereas DCL is a rare manifestation of leishmaniasis characterized by the presence of nodular, non-ulcerated lesions with abundant parasitized macrophages and the absence of an anti-Leishmania cell mediated immune response [2]. In Brazil, DCL is concentrated in the north and northeastern regions, with the highest number of cases being reported in the State of Maranhão [3]. L. amazonensis has also been isolated from patients with visceral leishmaniasis (VL) and from patients with muco-cutaneous leishmaniasis (ML), although, in Brazil, these two clinical manifestation are most generally associated with infection by L. chagasi and L. braziliensis [4], respectively.

A number of methods have been applied to or developed in order to study genetic diversity and relationships within Leishmania [5-8]. Among these, we can highlight PCR-based methods such as Random Amplification of Polymorphic DNA (RAPD-PCR) [9] and Simple Sequence Repeat (SSR-PCR) [10]. RAPD-PCR allows the detection of DNA polymorphisms without the need of pre-determined genetic data since it is based on the amplification of genomic DNA under low stringency conditions whereas SSR-PCR is based on amplification of inter-repeat segments using anchored oligonucleotides complementary to the microsatellite repeats. Microsatellites or simple sequence repeats are present in most eukaryotic genomes and consist of tandem repeats of a simple motif of a few nucleotides $(<6)$ [11]. Both RAPD and SSR-PCR have been used in the study of genetic diversity of Leishmania [12-14]. Another PCR-based method to analyze genetic diversity is based on the amplification of the internal transcribed spacers (ITS), located within the rRNA gene array, followed by digestion with restriction enzymes, a method termed "Intergenic Region Typing" [15]. Moreover, the ITS sequences can also be used to generate information useful for phylogenetic reconstruction and molecular evolution studies [16].

Diversity within Leishmania has also been investigated at the chromosome level as seen by chromosome size polymorphism [17]. Large-scale chromosomal rearrangements have occurred between Old World and New World species [18] and the chromosome-size polymorphisms are frequently associated with repeated elements present at the telomeres or to the amplification/deletion process of tandemly repeated genes, as in the L. major miniexon gene locus, in chromosome 2 [19].

In the present study, we have examined the genetic variability of L. amazonensis strains obtained in northeastern Brazil, from patients with different clinical manifestations of the disease, ranging from typical LCL to the rare DCL. In order to do so, different molecular tools such as ITS sequencing, RAPD and SSR-PCR and hybridization of
PFGE-resolved chromosomes with gene-specific markers were employed.

\section{Results \\ rRNA sequencing and analysis}

To begin examining diversity at the interspecific level, the DNA segment containing ITS 1 and 2, as well as the $5.8 \mathrm{~S}$ RNA gene, was amplified by PCR using as template DNA from 17 L. amazonensis strains isolated from patients with different clinical manifestations of leishmaniasis, DNA from a reference L. amazonensis strain (M2269) and DNA from a L. major strain (MHOM/81/IL/Friedlin), which was used as an out-group (Table 1). Except for strain BA115 which was, therefore, omitted from subsequent analyses, PCR amplification yielded a product of $\sim 1.2 \mathrm{~kb}$ for all strains studied (data not shown). Sequencing of the amplification product revealed 1131 bp orthologous sites and saturation analyses showed no severe saturation, all positions were informative (data not shown). The data set was then subjected to the probability ratio test (LRT) approach. The model that best fit the pattern of nucleotide substitution for our dataset was the HKY85 model [20] plus gamma distribution of $\alpha=0.3641$ (indicating heterogeneity of the sites' substitution rates over time). Considering these findings, we performed a phylogenetic signal analysis and found $25.6 \%$ of unresolved trees in the likelihood mapping method. As seen in Fig. 1, the tree topology obtained using the HKY model plus gamma distribution revealed two internal nodes, with $100 \%$ bootstrap support, in which strains BA32, BA112 and BA75 are clustered. We can only speculate that the clade containing BA32, BA112 and BA75 could be a sister group of the clade containing the BA69, BA73, BA88, and BA137 strains since the boostrap value (58\%) was not meaningful.

All VL isolates (BA137, BA32 and BA112) were clustered in these two clades, with the exception of BA109. The remaining tree branches, however, were found to be unresolved and some strains, such as BA109, BA125 and BA276, were even found to be identical at this locus such. Interestingly, BA106, a DCL case documented outside Maranhão State, where this disease is endemic, remained in a separate node with bootstrap support of $72 \%$. This strain was isolated in Bahia State, in 1986, whereas the other two DCL strains studied (BA199 and BA276) were isolated from patients from Maranhão state, in 1989.

\section{Genetic polymorphism within L. amazonensis strains by RAPD and SSR-PCR}

We then compared the topology of phylogenetic tree obtained by ITS sequencing with the dendrograms generated by RAPD and SSR-PCR. Branches observed in the resulting RAPD or SSR-PCR dendrograms were not strongly supported by bootstrap analysis (data not 
Table I: Strains of Leishmania amazonensis used in this study

\begin{tabular}{|c|c|c|c|}
\hline Number & International code & Origin $^{a}$ & Pathologyb \\
\hline I & MHOM/BR/I985/BA32 & BA & $\mathrm{VL}$ \\
\hline 2 & MHOM/BR/I986/BAI06 & BA & $\mathrm{DCL}$ \\
\hline 3 & MHOM/BR/I987/BAI09 & BA & $\mathrm{VL}$ \\
\hline 4 & MHOM/BR/I987/BAII 2 & BA & $\mathrm{VL}$ \\
\hline 5 & MHOM/BR/I987/BAII 3 & BA & $\mathrm{MCL}$ \\
\hline 6 & MHOM/BR/I987/BAII4 & $\mathrm{BA}$ & $M C L$ \\
\hline 7 & MHOM/BR/I987/BAI 25 & BA & $\mathrm{LCL}$ \\
\hline 8 & MHOM/BR/I989/BAI 99 & MA & $\mathrm{DCL}$ \\
\hline 9 & MHOM/BR/I989/BA276 & MA & $\mathrm{DCL}$ \\
\hline 10 & MHOM/BR/I973/M2269 & PA & $\mathrm{LCL}$ \\
\hline II & $\mathrm{MHOM} / \mathrm{BR} / 85 / \mathrm{BA} 69$ & $\mathrm{BA}$ & $\mathrm{LCL}$ \\
\hline 12 & MHOM/BR/85/BA73 & BA & $\mathrm{LCL}$ \\
\hline 13 & MHOM/BR/85/BA75 & BA & $\mathrm{LCL}$ \\
\hline 14 & MHOM/BR/85/BA88 & $\mathrm{BA}$ & PKDL \\
\hline 15 & MHOM/BR/87/BAII 5 & BA & $\mathrm{LCL}$ \\
\hline 16 & MHOM/BR/87/BAI 37 & $\mathrm{BA}$ & VL \\
\hline 17 & MHOM/BR/90/BA336 & MA & $\mathrm{DCL}$ \\
\hline 17 & MHOM/BR/85/BA56 & $\mathrm{BA}$ & $\mathrm{LCL}$ \\
\hline 17 & MHOM/BR/00/BA77I & BA & $\mathrm{LCL}$ \\
\hline
\end{tabular}

aBA, Bahia, MA, Maranhão; PA, Pará.

bVL, Visceral Leishmaniasis; LCL, Localized Cutaneous Leishmaniasis; MCL, Muco-Cutaneous Leishmaniasis; DCL, Diffuse Cutaneous Leishmaniasis; PKDL, Post-Kalazar Dermal Leishmaniasis.

shown). A combined analysis of RAPD and SSR-PCR results is shown in Fig. 2. The grouping of BA109 and BA112 (both obtained from VL patients) as well as the grouping of strains BA113 and BA114 (both from ML patients) were supported by significant bootstrap values (91 and 98\%, respectively). In this combined analysis, BA106 (obtained from a DCL strain) also remained in a separate branch, as observed in the individuals RAPD and SSR-PCR dendrograms (data not shown). Overall, either by ITS, RAPD or SSR-PCR, we did not detect any association between genetic polymorphism and geographic origin.

\section{Chromosome size variations}

In order to investigate the degree of chromosome size polymorphism, chrosomomes from L. amazonensis BA106, BA109, BA113, BA125, BA276 which are representative of the leishmaniasis clinical manifestation spectrum, L. amazonensis M2269, L. braziliensis strain (MHOM/BR/94/ H3227) and L. major Friedlin were separated by PFGE and hybridized to specific chromosome markers. Fig. 3 shows the hybridization patterns observed for each marker used. The hybridization pattern indicates a wide variation in terms of chromosome size for the L. amazonensis strains studied. Hybridization with a gene present in both chromosomes 1 and 2 (Fig. 3A) shows variation in terms of chromosome size for the strains tested and, importantly, we observed size polymorphisms between chromosome homologues. A similar result was observed by hybridiza-

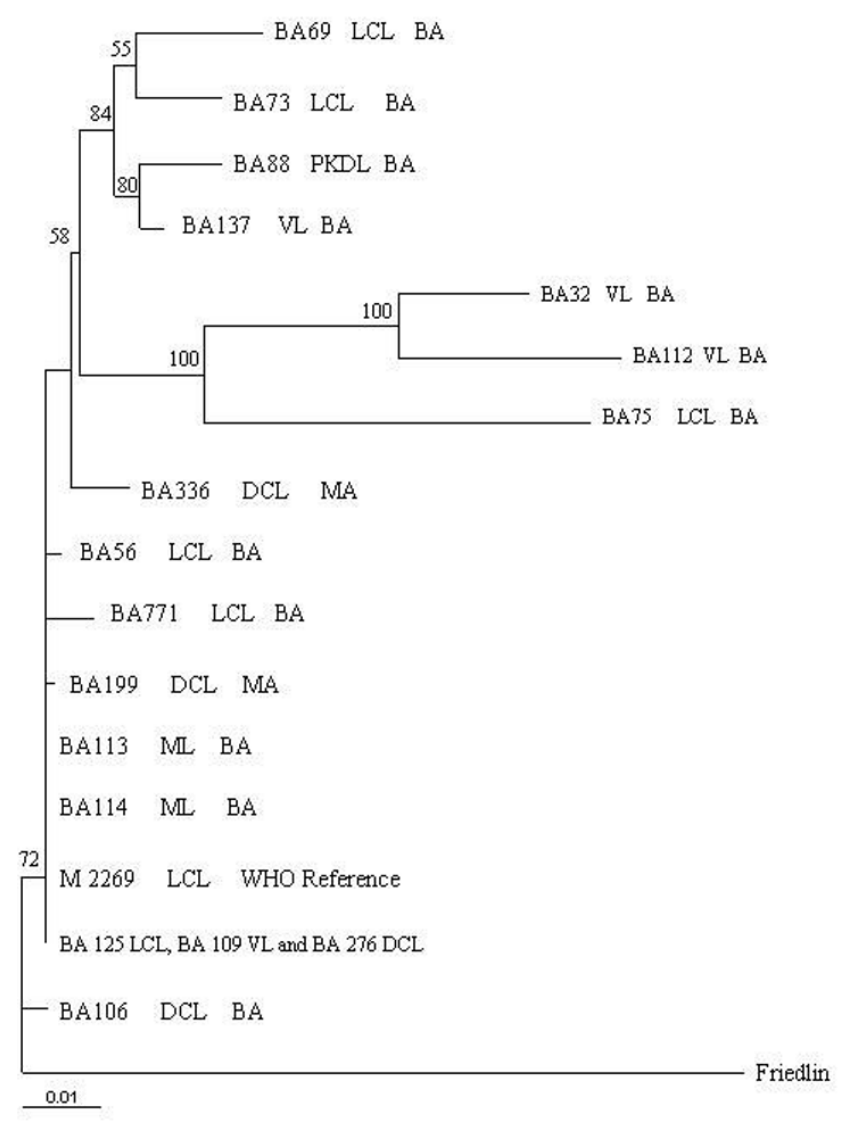

\section{Figure I}

Phylogenetic relationships among $L$. amazonensis strains inferred by Maximum likelihood analysis of the sequences of the ITSI, ITS2 and 5.8 S region. The numbers indicate the percentages with which a given branch is supported in 1000 bootstraps replications. The tree is rooted using $L$. major as outgroup.

tion with the spliced leader RNA gene present in chromosome 2 (Fig. 3B). In contrast, size polymorphism of chromosome 6 , identified by hybridization with the dihydrofolate reductase-thymidulate-synthase (DHFR-TS) gene (Fig. 3C) was less evident among the strains tested. The genomic clone used to identify chromosome 14 (Fig. 3D) has reiterated elements, which are present in other three larger chromosomes of $L$. major, therefore, it allowed the comparison of 4 chromosomes at a time. The results indicate a narrow size variation of these chromosomes within the L. amazonensis strains tested.

\section{Discussion}

Leishmania infection is characterized by a spectrum of disease manifestations ranging from a relatively benign LCL to the disfiguring ML or the potentially fatal VL and infection with L. amazonensis has been associated with these diverse clinical manifestations [1], including DCL. DCL is 


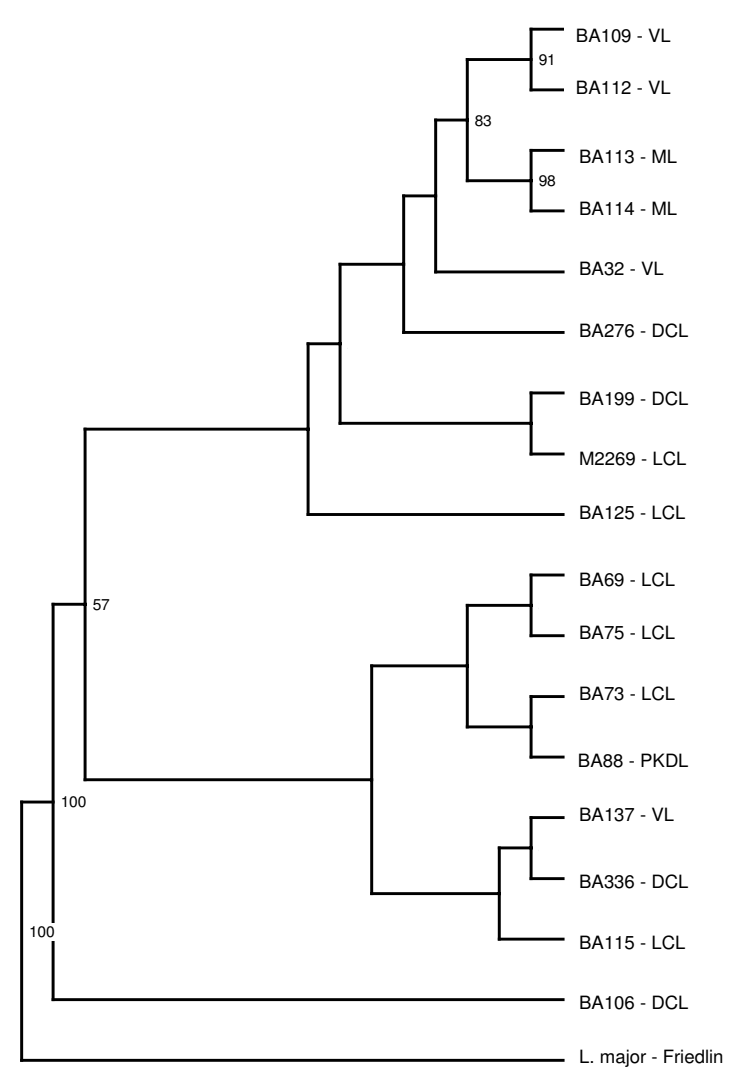

Figure 2

UPGMA dendrogram based on the combined RAPD and SSR-PCR amplification patterns obtained for $L$. amazonensis strains. Bootstrap values above $50 \%$ are indicated.

a rare disease, endemic to Maranhão State, solely associated with $L$. amazonensis infection [21]. In the present work, we examined, for the first time, the genetic diversity of L. amazonensis strains from northeastern Brazil, obtained from patients with distinct clinical manifestations of leishmaniasis employing different molecular techniques.

Phylogenetic relationship among strains was inferred based on the sequence comparison of a segment of the rRNA gene locus. The ITS are less conserved between species than rRNA genes and are therefore suitable for the phylogenetic characterization of closely related organisms [22]. The phylogenetic signal analysis showed a number of unresolved trees below 30\%, indicating that the data are reliable for phylogenetic inference [23]. Genetic polymorphism within this relatively conserved region has been shown for L. braziliensis and L. naiffi [15], L. donovani [24], L. aethiopica [25]. In the present study, ITS sequencing was able to discriminate a subset of the strains; particularly VL strains, although this particular VL clustering
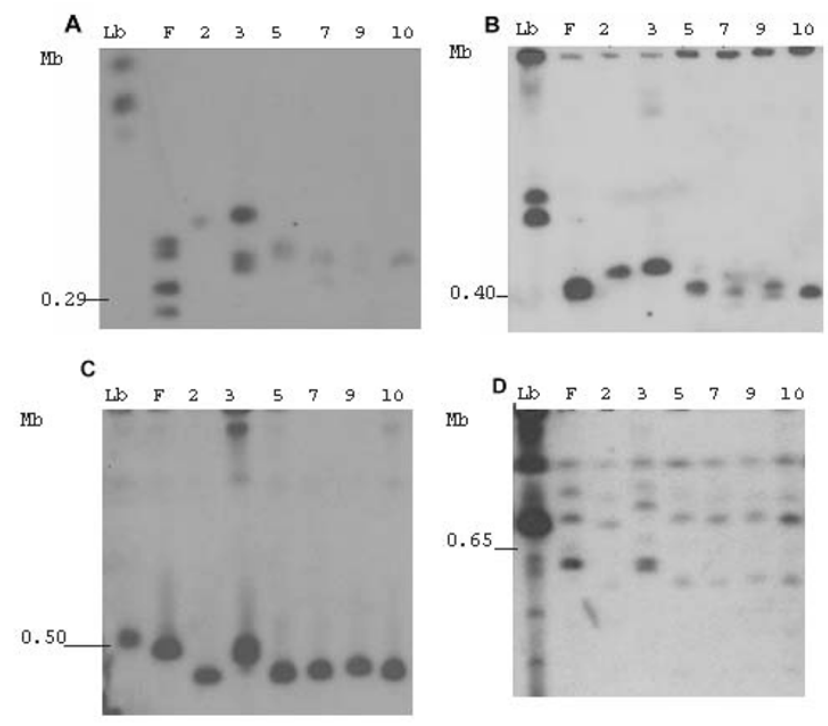

\section{Figure 3}

Pulsed Field Gel Electrophoresis resolved L. amazonensis chromosomes hybridized with chromosome-specific markers. Following PFGE, gels were blotted and hybridized to radiolabeled probes (A) oligopeptidase; (B) spliced leader RNA gene, (C), DHRF-TS and (D), the genomic fragment from a cosmid clone I0E07. Each lane corresponds to one $L$. amazonensis strain, identified by the number reported in Table I. Lb, L. braziliensis ; F, L. major ; Molecular size is shown at the left side of each panel, (Mb). L. major chromosome numbers of interest are numbered in the figure.

was not supported by bootstrap analysis. A conspicuous politomy was observed with the other strains studied, except for strain BA106, indicating a high similarity among the DNA sequences. Similarly, it has been shown that restriction fragment analysis of the ITS region did not reveal differences among L. mexicana strains [26].

We then examined the genetic diversity of $L$. amazonensis strains by RAPD and SSR-PCR since both techniques have been used to study genetic polymorphism among Leishmania strains [12-14]. In previous reports, genetic polymorphism could be correlated with the geographical origin of parasite strains [12,27-29]or clinical phenotype [30-32]. Recently, we have demonstrated that L. braziliensis isolates differing at the genome level also show distinctive infection patterns in BALB/c mice [33]. Herein, no association was found between genetic polymorphism and clinical manifestation of disease or geographical origin of isolate although such the search for these types of correlation was beyond the scope of the present work. On the other hand, we did observe a degree of genetic variability among the L. amazonensis strains employed here, particularly BA109, BA112 and BA106. The latter, isolated from a patient with DCL, was consistently grouped sepa- 
rately from all the other strains studied. This was first noted using ITS sequencing and was later confirmed by both RAPD and SSR-PCR. In the phylogenetic and RAPD analysis, BA106 presented the most basal divergence, sharing this position with the L. major strain. The occurrence of Leishmania stocks phenotipically similar to $L$. major, as assayed by enzyme electrophoresis and monoclonal antibodies, has been documented elsewhere [34]. We could speculate that BA106 is one of these strains, however, in another study, it was typed as L. amazonensis by enzyme electrophoresis and monoclonal antibodies[1]. Therefore, further characterization of this strain is needed in order to confirm the identity of BA106.

We also investigated the existence of size polymorphisms in terms of chromosome size since this is widespread phenomenon in trypanosomatids [35]. DNA from L. amazonensis strains was separated by PFGE and hybridized with chromosome specific markers, previously anchored to the chromosomes of L. major and other Old World species (P. Bastien, A. Cruz et al., unpublished data). We observed size variation of homologous chromosomes of L. amazonensis, when compared to L. major, as seen with chromosome 2, for example, indicating a possible amplification/ deletion of the miniexon array. Biological relevance for the intra-chromosome size variation of the miniexon array has never been reported, although previously observed [19,36,37]. More importantly, chromosome hybridization results for strain BA109 showed a size polymorphism pattern differing from all other strains analyzed, reinforcing the importance of studying the genome plasticity characteristic of Leishmania, particularly observed within neotropical strains $[38,39]$

\section{Conclusion}

In the present work, we have studied the genetic diversity within L. amazonensis strains from northeastern Brazil. We show that L. amazonensis strains isolated from patients with different clinical manifestations of the disease are genetically diverse and show that this divergence extends to variations in terms of chromosome size. Since L. amazonensis is associated with rare or unusual disease presentations such as DCL or VL, respectively, it remains of interest to search for genetic markers that can be associated with these clinical manifestations.

\section{Methods}

\section{Parasites isolates and genomic DNA preparation}

A total of $18 \mathrm{~L}$. amazonensis strains were used in this study (Table 1). Strains were obtained between 1985 and 1990 by aspiration of lesions from cutaneous, mucosal, diffuse and post-Kalazar dermal leishmaniasis or by bone marrow aspiration of visceral leishmaniasis patients, each isolate originated from a different human subject [1]. Strains have been maintained in cryopreservation tanks since the time of isolation in culture. For the purpose of this study, isolates were defrosted and cultured until a parasite density of $10^{7} / \mathrm{ml}$ was obtained. Species identification was performed by PCR [40] and by ELISA using monoclonal antibodies [41]. For genomic DNA extraction, stocks were grown in 199 medium supplemented with $10 \%$ heat inactivated fetal bovine serum (both from Invitrogen), at $26^{\circ} \mathrm{C}$. Parasites $\left(10^{7} / \mathrm{ml}\right)$ were harvested by centrifugation and genomic DNA was purified using Wizard ${ }^{\circledR}$ Genomic DNA Purification Kit (Promega). DNA was ressuspedend in $50 \mu \mathrm{l} \mathrm{TE}$ buffer ( $10 \mathrm{mM}$ Tris, $1 \mathrm{mM}$ EDTA, $\mathrm{pH} 8.0)$ and stored at $-20^{\circ} \mathrm{C}$ until used. DNA concentration was estimated by spectrophometry by reading the absorbance at $260 \mathrm{~nm}$. Sample purity was checked by agarose gel electrophoresis and ethidium bromide staining.

\section{ITS Sequencing and Analysis}

The segment containing the ITS 1, 2 and the $5.8 \mathrm{~S}$ region, within the rRNA gene locus, were amplified by PCR using primers IR1 (5'-GCTGTAGGTGAACCTGCAGCAGCTGGATCATT-3'), IR2 (5'-GCGGGTAGTCCTGCCAAACACTCAGGTCTG-3') [15] and an internal primer (5'-CGGCGCATGGGAGAAGCT3-3'). PCR products were purified with the CONCERT rapid PCR purification system (Gibco BRL), following the manufacturer's instructions. Amplified PCR products were sequenced in both strands in an $\mathrm{ABI} 377^{\circledR}$ system using the BigDye Terminator Cycle Sequencing Kit ${ }^{\circledast}$ (Applied Biosystems). Quality analysis and assembling of the sequences were performed using Phred/Phrap/Consed ${ }^{\circledR}$ package [42]. Consensus sequences with Phred quality $>15$ were locally aligned with sequences submitted to GenBank using Blast N program [43]. Consensus sequences were submitted to GenBank and are available under the accession numbers DQ300179-DQ300195. Sequence alignment was performed manually using the BIOEDIT software (v5.0.9) [44] and for all sequences, alignment was unambiguous. The mutational saturation was examined using PAUP* (v4.0b10) [45]. The nucleotide substitution model and the gamma distribution were obtained by the likelihood ratio test (LRT) [46], employing the MODELTEST software (v3.0b6) [47]. The phylogenetic signal was tested employing the TREE-PUZZLE (v 5.3) software [48], using the likelihood mapping method [49]. Maximum likelihood (ML) method was then performed in PAUP* (v4.0b10), with a starting tree obtained via NeighborJoining algorithm. The reliability of internal branches was assessed using the bootstrap method with 1000 pseudoreplicates. Tree topology was visualized using the TREEVIEW program ( $\mathrm{v}$ 1.6.2) [50]. The homologous sequence of $L$. major Friedlin strain (MHOM/IL/81/ FRIEDLIN) was adopted as the outgroup. 


\section{RAPD and SSR-PCR}

RAPD amplification was done as previously described [13], employing one the following primers: 3302 (5'CTGATGCTAC-3'); 3303 (5'-TCACGATGCA-3') and 3304 (5'-GCACTGTCA-3') (all from Invitrogen). Amplification was performed under the following conditions: an initial denaturation step at $95^{\circ} \mathrm{C}$ for $5 \mathrm{~min}$, two cycles with annealing at $30^{\circ} \mathrm{C}$ for $2 \mathrm{~min}$, extension at $72^{\circ} \mathrm{C}$ for $1 \mathrm{~min}$ and denaturation at $95^{\circ} \mathrm{C}$ for $30 \mathrm{~s}$, followed by 33 cycles in which the annealing temperature was increased to $40^{\circ} \mathrm{C}$. The final extension was carried for $5 \mathrm{~min}$ at $72^{\circ} \mathrm{C}$. SSR-PCR amplification was performed using two primers: [5'-(CA) ${ }_{8}$ RY-3'], which amplifies inter-repeat segments [10] and [5'-CAA(CT) $\left.)_{6}-3^{\prime}\right]$, which amplifies inter-repeat segments as well as the repeat segment [51]. Amplification reactions were performed under the following conditions: 26 cycles of denaturation at $94^{\circ} \mathrm{C}$ for $30 \mathrm{~s}$, annealing at $50^{\circ} \mathrm{C}$ for $45 \mathrm{~s}$ for the $\left[5^{\prime}-\mathrm{CAA}(\mathrm{CT})_{6-} 3^{\prime}\right]$ primer or at $57^{\circ} \mathrm{C}$ for $45 \mathrm{~s}$ for the [ $\left.5^{\prime}-(\mathrm{CA})_{8} \mathrm{RY}-3^{\prime}\right]$ primer and extension at $72^{\circ} \mathrm{C}$ for $7 \mathrm{~min}$. All reactions were performed in triplicate. The amplification patterns were visualized after electrophoresis in a $1.5 \%$ ethidium bromide-stained agarose gel.

\section{Genetic polymorphism analysis}

Amplicons were scored by eye and well-defined, reproducible bands (generated in at least three amplification reactions) were used to construct a binary table. Each amplification band was numbered and scored as present (1) or absent (0) and genetic similarity among strains was calculated using Jaccard's similarity coefficient. The relationships between strains were estimated through dendrograms representing RAPD and SSR-PCR data. Dendrograms were constructed based on a matrix of genetic distance through UPGMA [52] using FreeTree (v. 0.9.1.50) [53] and the bootstrap option was used to run 1000 replicates to obtain confidence estimates for the groupings.

Pulsed Field Gel Electrophoresis (PFGE) and Southern Blot Chromosomal DNA was prepared in low-melting temperature agarose plugs [54]. Chromosomes were separated by PFGE run on a contour-clamped homogeneous electric field apparatus (CHEF DR II, BioRad). Gels were run at $14^{\circ} \mathrm{C}$, at $6.0 \mathrm{~V} \mathrm{~cm}^{-1}$ for $28 \mathrm{~h}$ with a 35.4 - to 73.6 -s pulse ramp time. Electrophoresed DNAs were transferred to nylon membranes (GeneScreen Plus).

\section{Probes and hybridization}

Four probes were used in this study in order to explore size-polymorphisms of some chromosomes (1, 2, 6 and 14). These were (i) a L. major oligopeptidase gene, present in the extremities of chromosomes 1, 2 and 27 of L. major; (ii) a L. major spliced leader RNA gene, present in chromosome 2; (iii) a L. major dihydrofolate reductase-thymidulate-synthase (DHRF-TS) present in chromosome 6 and (iv) a L. major genomic fragment from chromosome 14 (cosmid 10E07), which has internal elements repeated in three other larger chromosomes of L. major (A.K. Cruz, unpublished results). All probes were labeled with $[\alpha-$ $\left.{ }^{32} \mathrm{P}\right] \mathrm{dCTP}$ by random priming. Hybridization and washing conditions were performed as described [37] and membranes were exposed at $-70^{\circ} \mathrm{C}$ with an intensifying screen.

\section{Competing interests}

The author(s) declare that they have no competing interests.

\section{Authors' contributions}

JPCO carried out DNA extraction, DNA hybridization, sequence alignment, phylogenetic analysis and dendrogram constructions. FF participated in sequence alignment, phylogenetic analysis and helped to draft the manuscript. AKC participated in the design of the study and helped to draft the manuscript. VT carried out DNA hybridization. AAC participated in the design of the study and helped to draft the manuscript. EM carried out DNA sequencing. $\mathrm{AB}$ participated in study design and coordination and helped to draft the manuscript. CIO conceived of the study, participated in its design and coordination and drafted the manuscript. All authors read and approved the final manuscript.

\section{Acknowledgements}

We thank Lucile Floeter-Winter for critical reading of the manuscript and Artur T.L. de Queiroz for initial help with phylogenetic analysis. This work is supported by grants from CNPq, FAPESB and PAPES/FIOCRUZ. J.P.C. de Oliveira was supported by a CNPq fellowship; C.I.O. and F.M.C.F were supported by a FAPESB fellowship. $A A C, A B$, and $C I O$ are senior investigators from $C N P q . A B$ is a senior investigator for Instituto de Investigação em Imunologia (iii).

\section{References}

I. Barral A, Pedral-Sampaio D, Grimaldi Junior G, Momen H, McMahonPratt D, Ribeiro de Jesus A, Almeida R, Badaro R, Barral-Netto M, Carvalho EM, et al.: Leishmaniasis in Bahia, Brazil: evidence that Leishmania amazonensis produces a wide spectrum of clinical disease. The American Journal of Tropical Medicine and Hygiene 1991, 44(5):536-546.

2. Barral A, Costa JM, Bittencourt AL, Barral-Netto M, Carvalho EM: Polar and subpolar diffuse cutaneous leishmaniasis in Brazil: clinical and immunopathologic aspects. Int J Dermatol 1995, 34(7):474-479.

3. Costa JML, Cunha AK, Gama MEA, Saldanha ACR: Leishmaniose cutânea difusa: revisão. An Bras Derm 1998, 73:565-576.

4. Marsden PD: Mucocutaneous leishmaniasis. Bmj 1990, 30I(6753):656-657.

5. Miles MA, Povoa MM, de Souza AA, Lainson R, Shaw IJ: Some methods for the enzymic characterization of Latin-American Leishmania with particular reference to Leishmania mexicana amazonensis and subspecies of Leishmania hertigi. Transactions of the Royal Society of Tropical Medicine and Hygiene 1980, 74(2):243-252.

6. Tibayrenc M, Neubauer K, Barnabe C, Guerrini F, Skarecky D, Ayala FJ: Genetic characterization of six parasitic protozoa: parity between random-primer DNA typing and multilocus enzyme electrophoresis. Proceedings of the National Academy of Sciences, USA 1993, 90(4): 1335-1339. 
7. Jackson PR, Wohlhieter JA, Jackson JE, Sayles P, Diggs CL, Hockmeyer WT: Restriction endonuclease analysis of Leishmania kinetoplast DNA characterizes parasites responsible for visceral and cutaneous disease. The American Journal of Tropical Medicine and Hygiene 1984, 33(5):808-819.

8. Macedo AM, Melo MN, Gomes RF, Pena SD: DNA fingerprints: a tool for identification and determination of the relationships between species and strains of Leishmania. Molecular and Biochemical Parasitology 1992, 53( I-2):63-70.

9. Williams JG, Kubelik AR, Livak KJ, Rafalski JA, Tingey SV: DNA polymorphisms amplified by arbitrary primers are useful as genetic markers. Nucleic Acids Res 1990, 18(22):653 I-6535.

10. Zietkiewicz E, Rafalski A, Labuda D: Genome fingerprinting by simple sequence repeat (SSR)-anchored polymerase chain reaction amplification. Genomics 1994, 20(2): I76-183.

II. Rubinsztein DC, Amos W, Leggo J, Goodburn S, Jain S, Li SH, Margolis RL, Ross CA, Ferguson-Smith MA: Microsatellite evolution--evidence for directionality and variation in rate between species. Nat Genet 1995, 10(3):337-343.

12. Gomes RF, Macedo AM, Pena SD, Melo MN: Leishmania (Viannia) braziliensis: genetic relationships between strains isolated from different areas of Brazil as revealed by DNA fingerprinting and RAPD. Experimental Parasitology 1995, 80(4):68|-687.

13. Volpini AC, de Azeredo Passos VM, Romanha AJ: Attempt to differentiate Leishmania (Leishmania) amazonensis, $L$. (L.) chagasi, Leishmania (Viannia) braziliensis and L. (V.) guyanensis using the SSR-PCR technique. Parasitolology Research 200I, 87(12): 1056-1059.

14. Schriefer A, Schriefer AL, Goes-Neto A, Guimaraes LH, Carvalho LP, Almeida RP, Machado PR, Lessa HA, de Jesus AR, Riley LW, Carvalho EM: Multiclonal Leishmania braziliensis population structure and its clinical implication in a region of endemicity for American tegumentary leishmaniasis. Infect Immun 2004, 72(I):508-5I4.

15. Cupolillo E, Grimaldi Junior G, Momen H, Beverley SM: Intergenic region typing (IRT): a rapid molecular approach to the characterization and evolution of Leishmania. Molecular and Biochemical Parasitology 1995, 73(I-2): I45-155.

16. Davila AM, Momen H: Internal-transcribed-spacer (ITS) sequences used to explore phylogenetic relationships within Leishmania. Ann Trop Med Parasitol 2000, 94(6):65I-654.

17. Pages M, Bastien P, Veas F, Rossi V, Bellis M, Wincker P, Rioux JA, Roizes G: Chromosome size and number polymorphisms in Leishmania infantum suggest amplification/deletion and possible genetic exchange. Mol Biochem Parasitol 1989, 36(2): $16 \mid-168$.

18. Britto C, Ravel C, Bastien P, Blaineau C, Pages M, Dedet JP, Wincker $P$ : Conserved linkage groups associated with large-scale chromosomal rearrangements between Old World and New World Leishmania genomes. Gene 1998, 222(1): 107-I I7.

19. lovannisci DM, Beverley SM: Structural alterations of chromosome $\mathbf{2}$ in Leishmania major as evidence for diploidy, including spontaneous amplification of the mini-exon array. Mol Biochem Parasitol 1989, 34(2): I77-I88.

20. Hasegawa M, Kishino H, Yano T: Dating of the human-ape splitting by a molecular clock of mitochondrial DNA. J Mol Evol 1985, 22(2):160-174.

21. Bittencourt A, Barral A, de Jesus AR, de Almeida RP, Grimaldi Junior G: In situ identification of Leishmania amazonensis associated with diffuse cutaneous leishmaniasis in Bahia, Brazil. Memórias do Instituto Oswaldo Cruz 1989, 84(4):585-586.

22. Hillis DM, Dixon MT: Ribosomal DNA: molecular evolution and phylogenetic inference. $Q$ Rev Biol 1991, 66(4):4I I-453.

23. von Haeseler A, Strimmer K: Phylogeny inference based on maximum-likelihood methods with TREE-PUZZLE. In The Phylogenetic Handbook: a pratical approach to DNA and protein phylogeny Edited by: Salemi M, Vandamme AM. Cambridge , Cambridge University Press; 2003.

24. EI Tai NO, El Fari M, Mauricio I, Miles MA, Oskam L, El Safi SH, Presber WH, Schonian G: Leishmania donovani: intraspecific polymorphisms of Sudanese isolates revealed by PCR-based analyses and DNA sequencing. Exp Parasitol 200I, 97(I):35-44.

25. Schonian G, Akuffo H, Lewin S, Maasho K, Nylen S, Pratlong F, Eisenberger CL, Schnur LF, Presber W: Genetic variability within the species Leishmania aethiopica does not correlate with clinical variations of cutaneous leishmaniasis. Molecular and Biochemical Parasitology 2000, 106(2):239-248.

26. Berzunza-Cruz M, Cabrera N, Crippa-Rossi M, Sosa Cabrera T, Perez-Montfort R, Becker I: Polymorphism analysis of the internal transcribed spacer and small subunit of ribosomal RNA genes of Leishmania mexicana. Parasitolology Research 2002, 88(10):918-925.

27. Ishikawa EA, Silveira FT, Magalhaes AL, Guerra junior RB, Melo MN, Gomes R, Silveira TG, Shaw J]: Genetic variation in populations of Leishmania species in Brazil. Transactions of the Royal Society of Tropical Medicine and Hygiene 2002, 96 SuppI I:SI I I-2I.

28. Cupolillo E, Brahim LR, Toaldo CB, de Oliveira-Neto MP, de Brito ME, Falqueto A, de Farias Naiff M, Grimaldi G Jr.: Genetic polymorphism and molecular epidemiology of Leishmania (Viannia) braziliensis from different hosts and geographic areas in Brazil. Journal of Clinical Microbiology 2003, 4 I (7):3 I26-3I32.

29. Zemanova E, Jirku M, Mauricio IL, Miles MA, Lukes J: Genetic polymorphism within the leishmania donovani complex: correlation with geographic origin. The American Journal of Tropical Medicine and Hygiene 2004, 70(6):613-617.

30. Berzunza-Cruz M, Bricaire G, Romero SZ, Perez-Becker R, SaavedraLira E, Perez-Montfort R, Crippa-Rossi M, Velasco-Castrejon O, Becker I: Leishmania mexicana mexicana: genetic heterogeneity of mexican isolates revealed by restriction length polymorphism analysis of kinetoplast DNA. Experimental Parasitology 2000, 95(4):277-284.

3I. Sreenivas G, Raju BV, Singh R, Selvapandiyan A, Duncan R, Sarkar D, Nakhasi HL, Salotra P: DNA polymorphism assay distinguishes isolates of Leishmania donovani that cause kala-azar from those that cause post-kala-azar dermal Leishmaniasis in humans. Journal of Clinical Microbiology 2004, 42(4): I739-174I.

32. Mahdi M, Elamin EM, Melville SE, Musa AM, Blackwell JM, Mukhtar MM, Elhassan AM, Ibrahim ME: Sudanese mucosal leishmaniasis: isolation of a parasite within the Leishmania donovani complex that differs genotypically from $L$. donovani causing classical visceral leishmaniasis. Infection, Genetics and Evolution 2005, 5(I):29-33.

33. Indiani de Oliveira C, Teixeira MJ, Teixeira CR, Ramos de Jesus J, Bomura Rosato A, Santa da Silva J, Brodskyn C, Barral-Netto M, Barral A: Leishmania braziliensis isolates differing at the genome level display distinctive features in BALB/c mice. Microbes and Infection 2004, 6(I I):977-984.

34. Momen H, Grimaldi G Jr., Pacheco RS, Jaffe CL, McMahon-Pratt D, Marzochi MC: Brazilian Leishmania stocks phenotypically similar to Leishmania major. The American Journal of Tropical Medicine and Hygiene 1985, 34(6): 1076-1084.

35. Blaineau C, Bastien P, Rioux JA, Roizes G, Pages M: Long-range restriction maps of size-variable homologous chromosomes in Leishmania infantum. Mol Biochem Parasitol 1991, 46(2):292-302.

36. Kebede A, De Doncker S, Arevalo J, Le Ray D, Dujardin JC: Size-polymorphism of mini-exon gene-bearing chromosomes among natural populations of Leishmania, subgenus Viannia. Int J Parasitol 1999, 29(4):549-557.

37. Antoniazi S, Lima HC, Cruz AK: Overexpression of miniexon gene decreases virulence of Leishmania major in BALB/c mice in vivo. Mol Biochem Parasitol 2000, 107(1):57-69.

38. Dujardin JC, Gajendran N, Arevalo J, Llanos-Cuentas A, Guerra H, Gomez J, Arroyo J, De Doncker S, Jacquet D, Hamers R, et al.: Karyotype polymorphism and conserved characters in the Leishmania (Viannia) braziliensis complex explored with chromosome-derived probes. Ann Soc Belg Med Trop 1993 , 73(2): $101-118$.

39. Dujardin JC, Dujardin JP, Tibayrenc M, Timperman G, De Doncker S Jacquet D, Arevalo J, Llanos-Cuentas A, Guerra H, Bermudez $\mathrm{H}$, et al: Karyotype plasticity in neotropical Leishmania: an index for measuring genomic distance among $L$. (V.) peruviana and $L$. (V.) braziliensis populations. Parasitology I995, I I 0 ( Pt I):2 I-30.

40. Castilho TM, Shaw J], Floeter-Winter LM: New PCR assay using glucose-6-phosphate dehydrogenase for identification of Leishmania species. J Clin Microbiol 2003, 4 I (2):540-546.

4I. McMahon-Pratt D, Bennett E, David IR: Monoclonal antibodies that distinguish subspecies of Leishmania braziliensis. The Journal Immunology I 982, I 29(3):926-927.

42. Phred/Phrap/Consed [http://www.phrap.org]

43. BlastN [http://www.ncbi.nlm.nih.gov] 
44. Hall A: BioEdit: a user-friendly biological sequence alignment editor and analysis program for Windows 95/98/NT. 1999, 41:46-49.

45. Swofford DL: 2003. PAUP* beta version. Phylogenetic Analysis Using Parsimony (*and other methods). Version 4. Sinauer Associates, Sunderland, Massachusetts.

46. Huelsenbeck JP: Is the Felsenstein zone a fly trap? Syst Biol 1997, 46(I):69-74

47. Posada D, Crandall KA: MODELTEST: testing the model of DNA substitution. Bioinformatics 1998, I4(9):817-818.

48. Schmidt HA, Strimmer K, Vingron M, von Haeseler A: TREE-PUZZLE: maximum likelihood phylogenetic analysis using quartets and parallel computing. Bioinformatics 2002, I 8(3):502-504.

49. Strimmer K, von Haeseler A: Likelihood-mapping: a simple method to visualize phylogenetic content of a sequence alignment. Proc Natl Acad Sci U S A 1997, 94( I3):68I5-68I9.

50. Page RD: TreeView: an application to display phylogenetic trees on personal computers. Comput Appl Biosci 1996, I 2(4):357-358.

5I. Wu KS, Jones R, Danneberger L, Scolnik PA: Detection of microsatellite polymorphisms without cloning. Nucleic Acids Res 1994, 22( I 5):3257-3258.

52. Sneath PH, Sokal RR: Numerical taxonomy. San Francisco, Freeman; 1973.

53. Pavlicek A, Hrda S, Flegr J: Free-Tree--freeware program for construction of phylogenetic trees on the basis of distance data and bootstrap/jackknife analysis of the tree robustness. Application in the RAPD analysis of genus Frenkelia. Folia Biol (Praha) 1999, 45(3):97-99.

54. Cruz A, Beverley SM: Gene replacement in parasitic protozoa. Nature 1990, 348(6297): I71-I73.

Publish with Bio Med Central and every scientist can read your work free of charge

"BioMed Central will be the most significant development for disseminating the results of biomedical research in our lifetime. "

Sir Paul Nurse, Cancer Research UK

Your research papers will be:

- available free of charge to the entire biomedical community

- peer reviewed and published immediately upon acceptance

- cited in PubMed and archived on PubMed Central

- yours - you keep the copyright

Submit your manuscript here:

http://www.biomedcentral.com/info/publishing_adv.asp
BiolMedcentral 